\title{
GCM grid-box choice and predictor selection associated with statistical downscaling of daily precipitation over Northern Ireland
}

\author{
Thomas Crawford, Nicholas L. Betts*, David Favis-Mortlock \\ School of Geography, Archaeology and Palaeoecology, Queen's University Belfast, Belfast BT7 1NN, UK
}

\begin{abstract}
Statistical downscaling bridges the gap between General Circulation Model (GCM) output and climate-impacts modellers' requirements. Recent development of user-friendly software has facilitated use of statistical downscaling methods by the wider climate-impacts community. Simplicity of use, however, does not imply underlying conceptual simplicity. Ostensibly innocuous choices made when parameterizing such downscaling tools can have major implications for output and the impact study. Issues of predictor variable selection and GCM grid-box choice in downscaling daily precipitation occurrence and amount are investigated using the Statistical DownScaling Model (SDSM) package version 3.1. Choices are discussed within the context of Northern Ireland (NIR), designated an oceanic grid box in GCMs' land-sea mask. Use of the Republic of Ireland (IR) grid box, or combination of IR and Scottish Borders (SB) grid boxes to represent the NIR grid box, are evaluated by identifying site-specific optimum predictor sets for a NIR precipitation network. Realism of contrasts evident in dominance and spatial pattern of predictors are discussed with reference to spatial and temporal characteristics of local climate and large-scale atmospheric processes. For example, NIR grid-box predictor output displays weaker spatial contrasts in spring and summer than its IR counterpart. Explained variance associated with grid box/predictor set combinations is $~ 25 \%$, similar to other precipitation downscaling studies. Differences of explained variance between grid boxes are $\sim 5 \%$, an attractive gain when modelling daily precipitation using statistical downscaling (SD), where 'improvement' of explained variance is at a premium. Future projections indicate more pronounced precipitation intensity using the NIR grid box. Overall, IR grid-box output appears most appropriate for downscaling of NIR daily precipitation. The NIR case study highlights the impact of predictor choice and grid-box selection upon SD output, particularly when the land area is represented by an oceanic grid box in GCM experiments.
\end{abstract}

KEY WORDS: Statistical downscaling $\cdot$ Daily precipitation $\cdot$ Predictor variables $\cdot$ General Circulation Model $\cdot$ GCM $\cdot$ Land-sea mask $\cdot$ Statistical DownScaling Model $\cdot$ SDSM $\cdot$ Northern Ireland

\section{INTRODUCTION}

Climate-impacts modellers typically require atmospheric data at spatial and temporal resolutions exceeding that of General Circulation Model (GCM) output. Statistical downscaling bridges the gap between GCM provision and climate-impacts modellers' requirements. Available for over a decade, use of statistical downscaling (SD) techniques was traditionally restricted to specialist research centres (UNFCCC 2005).
Diaz-Nieto \& Wilby (2005) note that uptake of SD techniques by the climate-impacts community was hindered by lack of awareness and user-orientated software. Recent software development has facilitated use of SD by the wider climate-impacts community. Climate-impacts modellers with relatively little knowledge of atmospheric physics are now able to create their own local or site-specific climate change scenarios. This increased accessibility can be precarious, with the danger that simplicity of use can give rise to 
a false perception of an underlying conceptual simplicity to these downscaling models. In using them, ostensibly innocuous choices must be made that strongly shape the characteristics of resultant climate projections.

The present study examines issues regarding selection of predictor variables and choice of climate model grid box(es) for downscaling daily precipitation (occurrence and amount) when applying an 'off-the-shelf' Statistical DownScaling Model (SDSM) package (version 3.1, Wilby \& Dawson 2004) as the climate component of climate-impacts modelling, and considers the implications of such choices. Daily precipitation is an appropriate variable to evaluate given its relatively low predictability (compared with temperature), and hence scope for larger uncertainties to emerge from the development of the downscaling model. We argue that when working with this user-friendly software, a potential pitfall is that important decisions regarding downscaling models may be taken for granted. As an example, importance of grid-box selection and possibilities for optimum predictor sets are discussed within the context of Northern Ireland (NIR), a land area that is typically represented by an oceanic grid box in GCM experiments.

The case study of NIR has important connotations for those many other land areas that exist as oceanic grid boxes in GCM experiments, and have a west coast maritime climate regime. Furthermore, understanding how different processes operate at different sites, how precipitation characteristics may change in the future, and how changes may impact hydrological systems is a research priority. Recent floods in the urban areas of Belfast, Downpatrick, Londonderry, Newcastle and Newry, serve as a reminder that climatic and hydrological variability can still have significant socio-economic impacts despite extensive investment in water and river management initiatives (Betts 2002a).

The present study begins by introducing the way in which NIR is represented in GCM experiments, and gives an overview of statistical downscaling. SDSM version 3.1 is then presented in its use as an 'off-theshelf' downscaling tool for the assessment of sitespecific climate change impacts. Focus then turns to discussion of optimum predictor sets derived from 2 contrasting grid boxes, offering climatologically meaningful reasons for the spatial and temporal contrasts in predictor selection. Climate projections for a single station are used to illustrate the markedly different precipitation projections that are created when different grid boxes are chosen. Finally, recommendations for good practice are identified, and implications discussed of the use of this downscaling technology by climate-impacts modellers in similarly sited locations elsewhere in the world.

\section{GCMs AND STATISTICAL DOWNSCALING}

GCMs are currently the most suitable tools for predicting future climate changes (IPCC 2001). However, 2 significant difficulties mean that direct use of GCM output is often inappropriate for climate-impacts modellers. First, GCMs cannot provide output at the spatial resolution required to represent processes of interest in many terrestrial impacts applications. Policy makers, planners and impact assessment groups are increasingly aware of the need to focus on the regional and local response of environmental systems to global climate change and variability (Wagener et al. 2005). Impact assessors typically require daily predictand (a surface climate variable such as precipitation) data on a local scale for a single country or region (Abaurrea \& Asín 2005). This mismatch between impact modeller requirement and GCM provision has resulted in development of numerous downscaling techniques, each with well documented advantages and disadvantages (Wilby \& Wigley 1997). Methods may be classified by technique used (IPCC-TGCIA 1999), or according to choice of predictor variables (Rummukainen 1997), although many downscaling approaches assume characteristics from several techniques.

A second difficulty is the mismatch existing between the land-sea mask of GCM global grids and the real global land surface. This is problematic, as the climate response over land grid boxes differs from that over ocean boxes (IPCC-TGCIA 1999). The SNIFFER (Scotland and Northern Ireland Forum For Environmental Research) report on implications of climate change for NIR identified that the grid box incorporating NIR comprised a high ocean/land ratio and effectively existed as ocean in the HadCM2 GCM used (Betts $2002 \mathrm{~b})$. This presented a problem of model output appropriateness within this box for application to future climate change scenarios for the region (Betts 2002b). The report was based upon the UKCIP98 (UK Climate Impacts Programme, 1998) climate scenarios (Hulme \& Jenkins 1998). The Hadley Centre for Climate Prediction and Research advised climate change for NIR be determined by averaging output from the Northern England and Republic of Ireland (IR) grid boxes (G. J. Jenkins pers. comm.). NIR is not unique in terms of both its climatology and the way it is represented on GCM grids. For example, the HadCM3 global grid comprises 7008 grid boxes, of which $\sim 2380$ boxes are $>50 \%$ land (by area), and are classified as such. Approximately 700 grid boxes, however, are $<50 \%$ land, and are thereby classified oceanic (N. Gedney pers. comm.).

While this misclassification may be insignificant when considering small islands or peninsulas extending into oceanic squares, there are areas—such as 
western coasts of North and South America, Africa and Europe-in which this land-sea delimitation will certainly impact upon the choice of grid box for downscaling approaches. This is a crucial choice; Wilby \& Wigley (2000) emphasise that choice of predictor variable and corresponding predictor domain, in terms of location and spatial extent, critically affect the realism and stability of downscaled precipitation scenarios.

SD comprises a search-using observed data-for a statistical relationship between the predictand to be downscaled and potential predictors (frequently the large-scale upper air variables), and, in a subsequent application of that relationship to GCM-produced data, for a future climate (Huth 2005). Reviews of the current state-of-the-art for SD (Prudhomme et al. 2002) reflect the diversity of approaches, including artificial neural network (ANN) methods (Hewitson \& Crane 1996), empirical orthogonal function (EOF) analyses (Benestad 2001), the analogue method (Zorita \& von Storch 1999) and multiple regression methods (Barrow et al. 1996). Haylock et al. (2006) provide a comprehensive review of the performances of several SD techniques, and their dynamical counterparts.

Downscaling approaches are integral components of a wide range of climate change impacts assessments, including shifts in river flow extremes (Pilling \& Jones 2002), regional landslide activity (Schmidt \& Glade 2003), forestry management plans (McCurdy \& Stewart 2003), changes in agroclimatic indices (Bootsma et al. 2005), crop production (Thomson et al. 2002), and modification of local disease patterns (Bernardi et al. 2006).

Predictor variable(s) selection is the most critical stage of the SD process. Across studies, however, a wide range of predictor variables has been employed, making comparative evaluation problematic. Indeed, it is often uncertain that the chosen predictors are the most climatologically meaningful in terms of their relevance for the site-specific predictand (Cavazos $\&$ Hewitson 2005).

Particularly problematic when selecting predictor variables is the need to attain a balance between, on the one hand, having a desirably parsimonious model, and on the other, adequately representing the physical processes of precipitation genesis. For downscaling precipitation, it is recommended that the predictor suite contains variables describing atmospheric circulation, thickness, stability and moisture content (Wilby $\&$ Dawson 2004). Models that downscale precipitation may include relatively few predictors yet should not just focus on an individual component of precipitation creation. For example, many studies focus on circulation indices, but such fields alone do not capture key precipitation mechanisms based on thermodynamics and water vapour content of the atmosphere, which are important factors in the character of precipitation (Cavazos \& Hewitson 2005). Using only such variables ignores the need to represent all aspects of the regional forcing, in order that the downscaling model remains valid under changing climatic conditions (Wilby et al. 2004). While large-scale atmospheric circulation may explain local precipitation behaviour, other variables not directly related to pressure (such as humidity and temperature in various atmospheric levels) can also play an important role (Abaurrea \& Asín 2005).

A practical consideration for creation of SD models, however, is that daily predictor variable selection is constrained by what data have been archived from climate model experiments. Furthermore, lower values of explained variance are more typical in downscaling models for daily precipitation than for more spatially uniform variables such as temperature. Explained variance achieved by precipitation models being typically 20 to $30 \%$, whereas temperature models may achieve $>70 \%$ (Mountain 2004). Wilby et al. (2002) emphasise, however, that it is not possible to specify an acceptable level of explained variance since model skill varies geographically, even for a common set of predictors.

$\mathrm{SD}$ is difficult to implement from first principles, and access to large observational and modelled data sets is necessary-along with considerable expertise in the field - to derive the statistical relationships (UNFCCC 2005). However, the end-user oriented software packages now available require little training for those familiar with climate science, but do require significant knowledge of the study area in order to establish realistic and meaningful statistical relationships.

\section{MODEL DESCRIPTION}

SDSM version 3.1 (Wilby \& Dawson 2004) is a Windows ${ }^{\mathrm{TM}}$-based decision support tool for assessment of regional climate change impacts. The model linearly conditions local-scale weather generator parameters (such as daily precipitation occurrence and amount) with reference to large-scale circulation patterns and atmospheric moisture variables (Table 1). This software package implements SD methods to produce high-resolution climate information from coarseresolution GCM simulations (UNFCCC 2005). SDSM represents a combination of multiple regression-based and stochastic weather generator methods (Wilby \& Dawson 2004). It may be categorised as a 'model output statistics method' in that the free atmospheric variables used to investigate statistical relationships are taken from reanalysis/GCM sources (Rummukainen 1997). 
Table 1. The UKSDSM candidate predictor variable suite

\begin{tabular}{|ll|}
\hline Predictor code & \multicolumn{1}{c|}{ Predictor description } \\
\hline mslp & Mean sea level pressure \\
p__f & Near surface airflow strength \\
p__u & Near surface zonal velocity component \\
p__v & Near surface meridional velocity component \\
p_z & Near surface vorticity \\
p_th & Near surface wind direction \\
p_zh & Near surface divergence \\
p5_f & $500 \mathrm{hPa}$ airflow strength \\
p5_u & $500 \mathrm{hPa}$ zonal velocity component \\
p5_v & $500 \mathrm{hPa}$ meridional velocity component \\
p5_z & $500 \mathrm{hPa}$ vorticity \\
p500 & $500 \mathrm{hPa}$ geopotential height \\
p5th & $500 \mathrm{hPa}$ wind direction \\
p5zh & $500 \mathrm{hPa}$ divergence \\
p8_f & 850 hPa airflow strength \\
p8_u & 850 hPa zonal velocity component \\
p8_v & 850 hPa meridional velocity component \\
p8_z & 850 hPa vorticity \\
p850 & 850 hPa geopotential height \\
p8th & 850 hPa wind direction \\
p8zh & 850 hPa divergence \\
r500 & Relative humidity at $500 \mathrm{hPa}$ \\
r850 & Relative humidity at $850 \mathrm{hPa}$ \\
rhum & Near surface relative humidity \\
s500 & Specific humidity at $500 \mathrm{hPa}$ \\
s850 & Specific humidity at $850 \mathrm{hPa}$ \\
shum & Near surface specific humidity \\
temp & Mean temperature at $2 \mathrm{~m}$ \\
&
\end{tabular}

SDSM is an innovative tool, making empirical downscaling accessible to the broader climate change impacts community (Wilby et al. 2002). The user-friendly interface of SDSM, and option of creating a candidate predictor suite that impact modellers do not have to extract, re-grid and normalise, allows a shift in focus from lengthy data processing and preparation to the creation of multiple ensembles of future climate scenarios from several GCM experiments. Other downscaling tools exist, but following rigorous assessment of the uncertainty of downscaled precipitation, daily maximum and minimum temperature, Khan et al. (2006) considered SDSM a more accessible and robust technique than the weather generator approach of LARS-WG (Long Ashton Research Station Weather Generator) and the mathematical method of ANN (Artificial Neural Network). They found SDSM capable of reproducing almost all statistical characteristics in its downscaled information at the $95 \%$ confidence level as found in observed data.

SDSM makes the downscaling process directly applicable for British impacts modellers by including a suite of daily predictor variables for 9 grid boxes covering the British Isles (Fig. 1). This grid matches the Hadley Centre's coupled atmosphere-ocean GCMs (AOGCMs), with each square measuring $2.5 \times 3.75^{\circ}$ (latitude $\times$ lon-

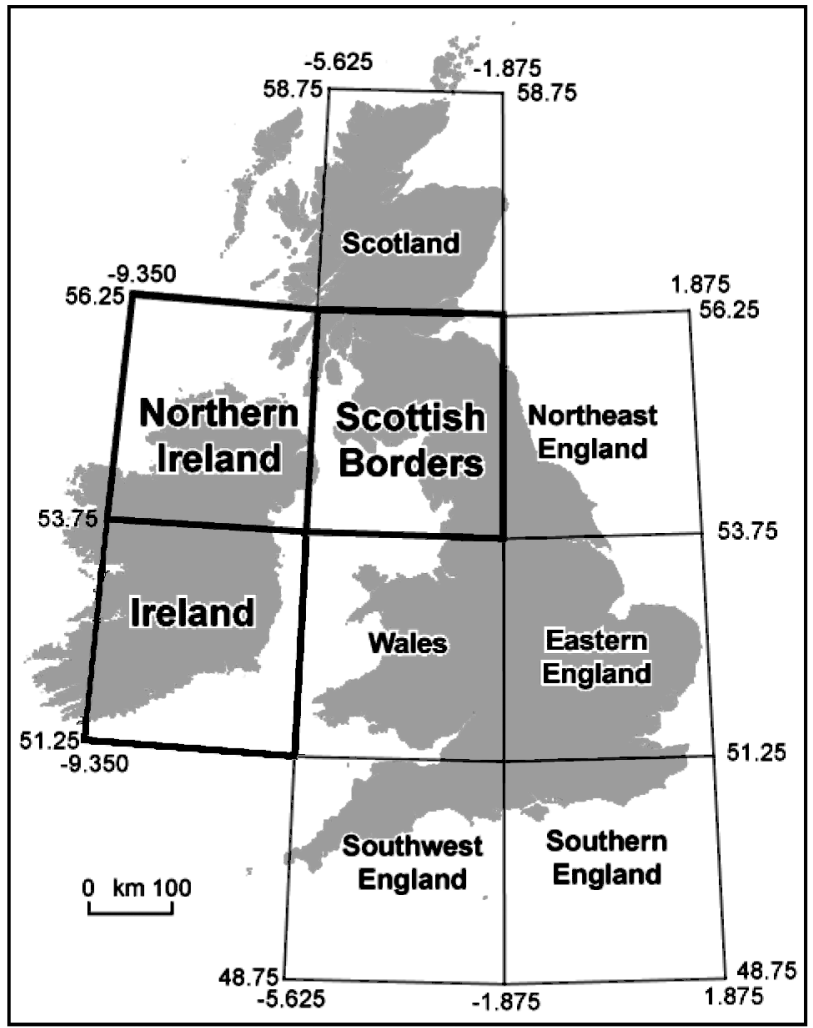

Fig. 1. Locations and names of the 9 grid boxes used in the UKSDSM data archive (after Wilby \& Dawson 2004)

gitude). Three of the 9 grid boxes-Northern Ireland, Northeast England and Southwest England (Fig. 1)are ocean grid boxes in the GCM experiments (Southern England, incorporating part of France, is a land grid box). To achieve more realistic forcing estimates for these grid boxes, data from the 2 nearest land grid boxes are averaged. For example, in the present study, predictor variables for NIR are obtained and averaged from the IR and Scottish Borders (SB) grid boxes, and termed the NIR grid box. Focusing upon data both from the NIR grid box and the IR grid box highlights the impact of grid-box choice. Harpham \& Wilby (2005) argue that downscaling of daily precipitation should involve use of both overlying and remote predictors. An added advantage is that combinations of grid boxes may remove some of the anomalies in GCM predictors produced by smoothing of the underlying topography (Harpham \& Wilby 2005). It is important to emphasise that the secondary airflow variables listed in Table 1 are all derived from $3 \times 3$ arrays of the pressure fields overlying the 'target' grid box (i.e. IR or NIR grid box). Therefore, predictor variables such as the zonal velocity component draw information from a larger domain than single grid-box variables such as relative humidity. Regardless of the box/array employed, downscaling from GCM grid boxes will always be susceptible to 
criticism based upon model inheritance of any fundamental biases in GCM output, such as misplaced storm tracks. For example, in the case of HadCM3, storm tracks over northwest Europe are likely displaced too far south (Hulme et al. 2002).

Given the paramount importance of the predictorpredictand relationship, the increased ease of use may translate into climate-impacts modellers naively treating SDSM as a model viewed purely in terms of the observable inputs and outputs, with the 'internals' of the system hidden from view, and without assumptions about behaviour or state beyond that specified by the interface (Battle 2003, available at: www.hpl.hp.com/ techreports/2003/HPL-2003-30.pdf). A balance must be sought between the relative convenience of the package, and the important choices regarding data that must still be made.

The SDSM process is outlined in Fig. 2, and the key questions implied at the stage prior to predictor selec- tion highlight the 5 key decisions about the predictorpredictand relationship that must be made: (1) Do local/remote grid boxes offer the most realistic correlation? (2) Do candidate predictors from the same/previous/subsequent day offer improvement? (3) Do individual sites follow any regional trends? (4) Do optimum predictor sets correspond with the local knowledge base of the precipitation regime? (5) Do predictors agree/disagree with those in the published literature?

\section{DATA AND METHODOLOGY}

The precipitation climatology of NIR reflects a location at the western extremity of a continental landmass, with maritime influences enhanced by heat transfer from neighbouring relatively warm North Atlantic surface water to the overlying atmosphere, and close proximity to depression tracks and associated

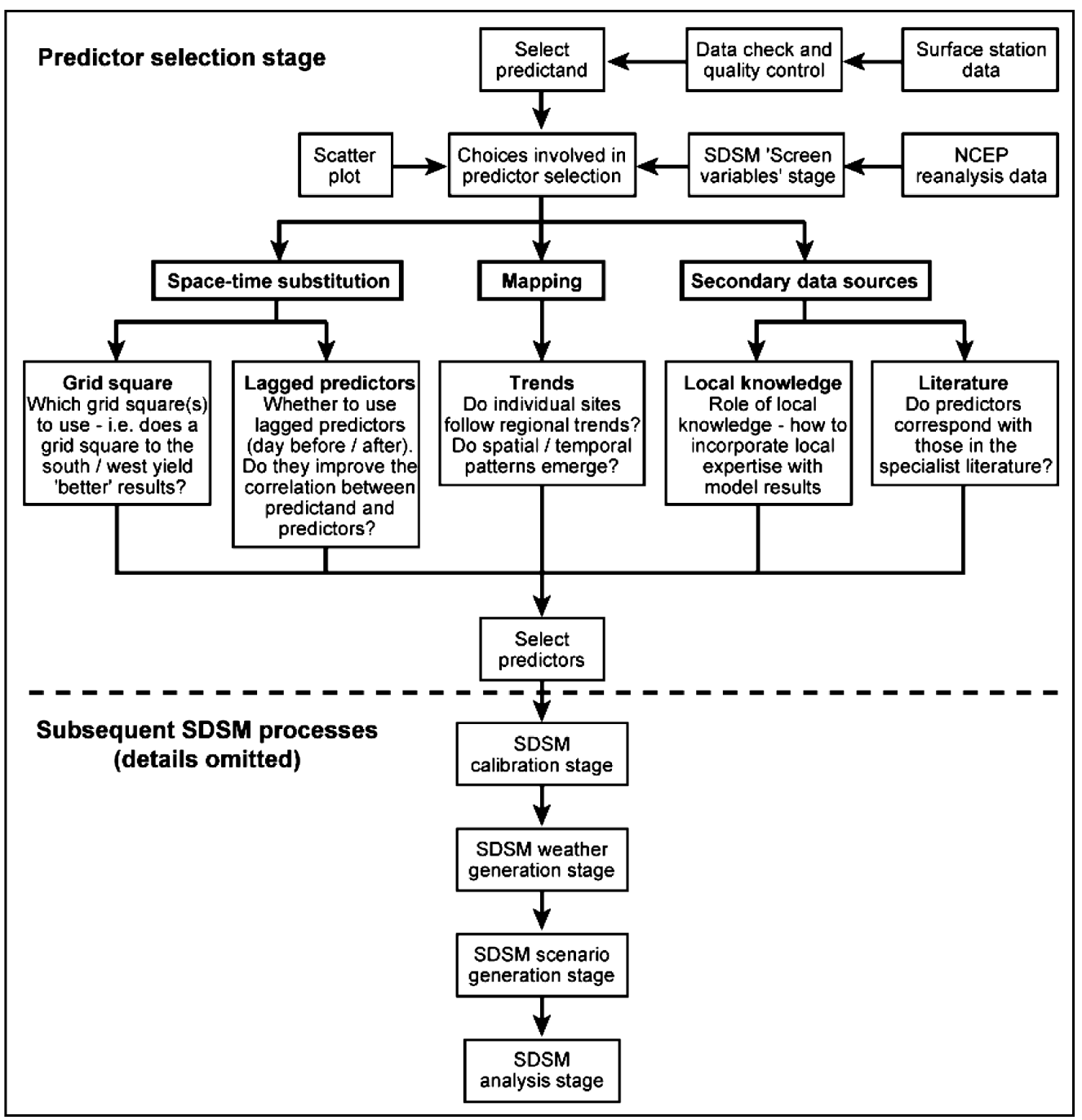

Fig. 2. SDSM processes, with emphasis on predictor selection stage (after Wilby \& Dawson 2004) 


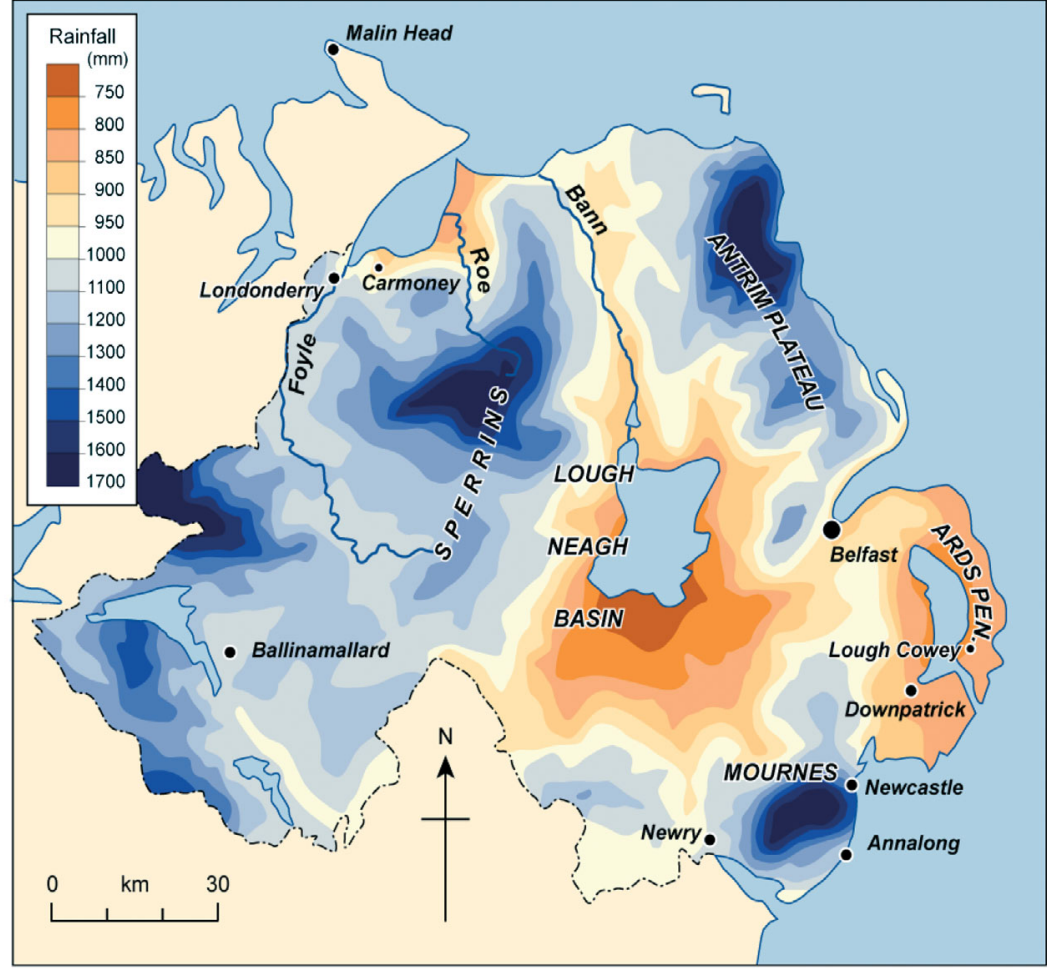

Fig. 3. Mean annual precipitation (mm) for Northern Ireland (NIR), 1961-1990 (after Betts 2002b). Also shown are locations of places mentioned in text

Observations data set via the British Atmospheric Data Centre (BADC). Stations were selected on the basis of completeness of the 1961-1990 daily precipitation record, and a suitable site network reflecting the main spatial pattern of precipitation across NIR. Representation of the extreme north of the study area was provided by the station Malin Head in the IR, and obtained from Met Éireann. SDSM version 3.1 was acquired from https://co-public. lboro.ac.uk/cocwd/SDSM/.

\subsection{Methodology}

The methodology used followed standard SDSM procedures, reflecting the steps that should be taken by a climateimpacts modelling group.

Step 1. Daily rainfall input files for each site were created following the standard settings described by Wilby \& Dawson (2004) for the period 1 January 1961 to 31 December 1990. The 'event threshold' was set to $0.3 \mathrm{~mm} \mathrm{~d}^{-1}$ to treat trace rain days as dry days. As

frontal systems (Betts 1997). The temporal and spatial patterns of precipitation receipt, however, are not uniform. Seasonal variation in NIR although not large, displays a wetter period between August and January. This pattern, and infrequency of heavy falls reflect the limited severe convectional activity in summer and moderately low topography. Within the relatively small land area of NIR $\left(\sim 14000 \mathrm{~km}^{2}\right)$, precipitation displays marked spatial variability, largely induced by local effects of topography (Betts 1997). Pronounced rain shadow effects are evident in the Foyle, Roe, and Bann valleys, Lough Neagh basin, and Ards peninsula, and prominent orographic enhancement of precipitation over the summits of the Mournes, Antrim Plateau and Sperrins (Fig. 3). Shelter afforded by adjacent upland in the IR, however, results in considerably lower precipitation, even at exposed upland sites, compared with Scotland and Wales. Complex interaction thereby exists between moisture sources, frontal activity within extra-tropical cyclones, local-scale convective processes and orographic ascent/sheltering processes.

\subsection{Data}

Daily precipitation data for 24 sites in NIR were obtained from the Met Office Land Surface Stations daily rainfall records are analysed with conditional models (i.e. modelling both occurrence and amount), and as the data are naturally skewed, a 4th root transformation was applied to the predictand files.

Step 2. A backward (previous day) and forward (subsequent day) lag was applied to both the IR and NIR grid-box candidate predictors. This is an important feature of the downscaling approach, with phrases such as 'location-for-time' or 'spatio-temporal substitution' (Harpham \& Wilby 2005) reflecting the substitution of observation in space for observation in time.

When studying NIR, this concept reflects real atmospheric processes in 2 ways. (1) The prevailing and interconnected influence of the meandering, upper westerly airstream (attaining maximum intensity at 200-300 hPa levels), mean depression tracks and nearsurface airflow regime result in frequent southwesterly flows. Thereby, IR's 'past' weather is often NIR's 'present' weather and the SB's 'future' weather. (2) Surface station measurements and NCEP reanalysis daily averages are not synchronous, with precipitation observations (0900 h GMT) being out of step with NCEP data (averaged at $1200 \mathrm{~h} \mathrm{GMT).}$

Step 3. The 'selection of downscaling predictor variables' stage identifies potentially fruitful predictorpredictand relationships. Whenever possible, predictor selection should be based on physical reasoning. For 
example, precipitation probability is related to vertical velocity and humidity. The vertical motion is often not available, but is correlated with the south-north wind component or with the temperature advection aloft. Hence, humidity parameters and parameters relating to temperature advection are likely to be useful for precipitation forecasts.

SDSM initially displays explanatory power on a monthly basis, but as all sites in this study displayed marked seasonality, the top 5 predictors for each season were identified for each site. The 5 predictors were shortlisted on the basis of their unique explanatory power (as given by the partial $\mathrm{r}$ statistic). These site-specific optimum predictor sets relating to each grid box were then mapped as pie-chart diagrams. Three to 6 optimum predictors are the norm in downscaling studies (Wilby \& Wigley 2000, Hanssen-Bauer et al. 2005). Justifications for a cut-off threshold at 5 predictors in the present study were that beyond this number, inclusion of further variables increased SD model noise and countered the SD ethos of selecting the most statistically meaningful controls on precipitation occurrence and amount (Huth 2005).

Step 4. The previous step identified how data from different grid boxes created different optimum predictor sets for each site, but did not contrast the differences in explained variance. To achieve this, the maximum and median $\mathrm{r}^{2}$ values from each grid box specific optimum predictor set were compared with their counterparts.

\section{RESULTS}

\subsection{Site-specific optimum predictor variables and grid-box selection}

The candidate predictor variable suite employed (Table 1) describes atmospheric circulation, thickness and moisture content at the surface, 850 and $500 \mathrm{hPa}$ levels - all integral determinants of conditions favourable/unfavourable for precipitation generation. Attempts to identify predictor-predictand relationships indicated that use of backward and forward lagged predictors in the form of previous and subsequent days, offered no advantage. Data from the previous day, whilst producing the same optimum predictors, generally produced marginally lower $\mathrm{r}^{2}$ values. Forward lagging procedures resulted in consistently low $\mathrm{r}^{2}$ values at all sites. This was probably due, in part, to the westerly location of the study area in relation to an adjoining grid box, and its limited spatial dimensions.

Figs. 4 \& 5 show the leading contemporaneous sitespecific predictor variables for the IR and NIR grid boxes as identified by a stepwise multiple linear re- gression procedure (SWLR) in the SDSM process using a $0.3 \mathrm{~mm} \mathrm{~d}^{-1}$ threshold for a coincident daily time step. Overall, secondary (airflow) variables tended to dominate over moisture variables for both grid boxes, with near surface relative humidity only a prominent selected variable in spring and summer. As found by Harpham \& Wilby (2005) in downscaling heavy precipitation occurrence over England, relative humidity at $850 \mathrm{hPa}$ and $500 \mathrm{hPa}$ levels were notable absentees given the prominence of humidity predictors in other studies (Beckmann \& Buishand 2002).

The leading predictor variables for NIR identified separately from the IR and NIR grid boxes, do not display propinquity between grids, and instead, exhibit contrasting seasonal variations in both dominance and spatial extent. The combinations of the 5 most heavily weighted predictors at each station derived from the IR grid box for all seasons delineate a discrete southeast area that contrasts with the remainder of NIR (Fig. 4). A similar, although less distinct delineation, is also evident in the predictor output from the NIR grid box (Fig. 5).

Of IR grid-box output, at all seasons zonal velocity at the near-surface, $850 \mathrm{hPa}$ and $500 \mathrm{hPa}$ levels, were the most frequently selected predictor variables of precipitation occurrence and amounts (Fig. 4). Surface relative humidity was a prominent predictor throughout NIR in spring and summer. Geopotential height at $850 \mathrm{hPa}$ and $500 \mathrm{hPa}$ levels were also prominent predictors in spring and summer over the southeast of NIR, and $500 \mathrm{hPa}$ airflow strength in autumn (September to November) and winter (December to February). Unlike previous analyses for the UK (e.g. Conway et al. 1996, Harpham \& Wilby 2005), vorticity was not a frequently selected variable for precipitation occurrence and amounts. Only in winter was surface vorticity selected, and then simply at sites in the extreme southeast.

In contrast, NIR grid-box output identified zonal velocity variables as being far less prominent predictors of precipitation occurrence and amounts. As with IR grid-box output, geopotential height at $850 \mathrm{hPa}$ and $500 \mathrm{hPa}$ levels were prominent predictors, but NIR grid-box data identified their broader spatial influence from spring through to autumn, with a southeast confinement only in winter (Fig. 5). Near-surface relative humidity was a prominent variable in spring and summer, but in contrast with IR grid-box output, vorticity at $850 \mathrm{hPa}$ was a leading predictor throughout NIR, accompanied by near surface vorticity in winter in eastern areas.

Data for both grid boxes identified airflow strength at $500 \mathrm{hPa}$ as a leading predictor variable in autumn, and to a lesser degree in winter. Its greater spatial extent across the station network, however, is evident using IR grid box data. 

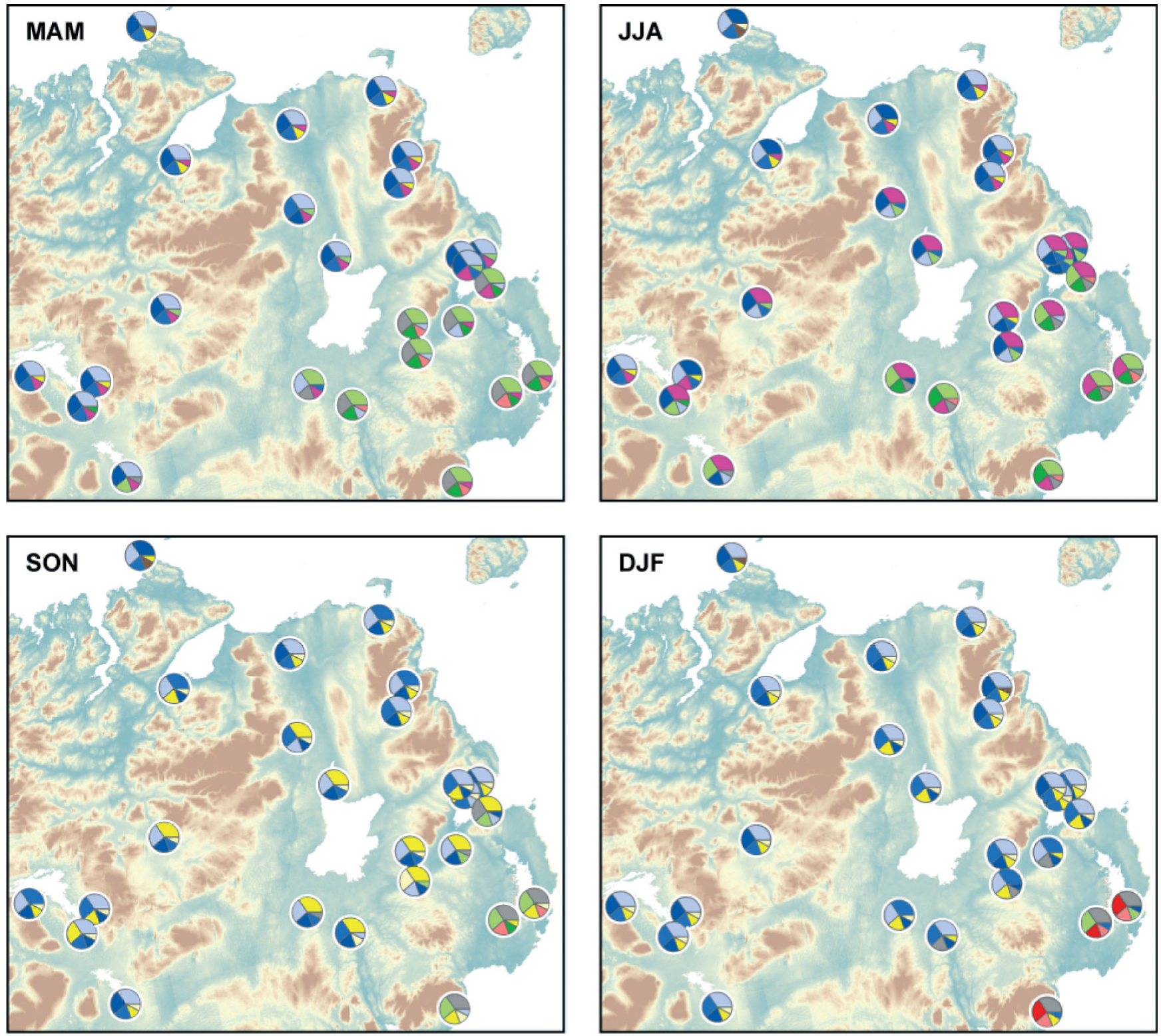

Near surface zonal velocity component $500 \mathrm{hPa}$ zonal velocity component $850 \mathrm{hPa}$ zonal velocity component Mean sea level pressure $500 \mathrm{hPa}$ geopotential height $850 \mathrm{hPa}$ geopotential height $500 \mathrm{hPa}$ airflow strength $850 \mathrm{hPa}$ airflow strength Near surface wind direction

Near surface vorticity 850 hPa vorticity

Near surface relative humidity
Atmospheric predictors for Grid Square IRELAND

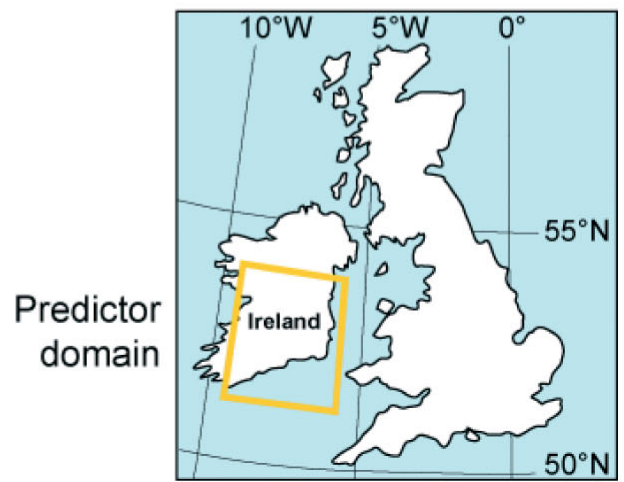

Fig. 4. Site-specific optimum predictor sets for Northern Ireland (NIR) when using the Republic of Ireland (IR) grid boxes. Site pie chart segment size reflects the ranked order of explained variance provided by each of the 5 optimum predictors (rank 1 largest to rank 5 smallest). MAM: March-May; JJA: June-August; SON: September-November; DJF: December-February 

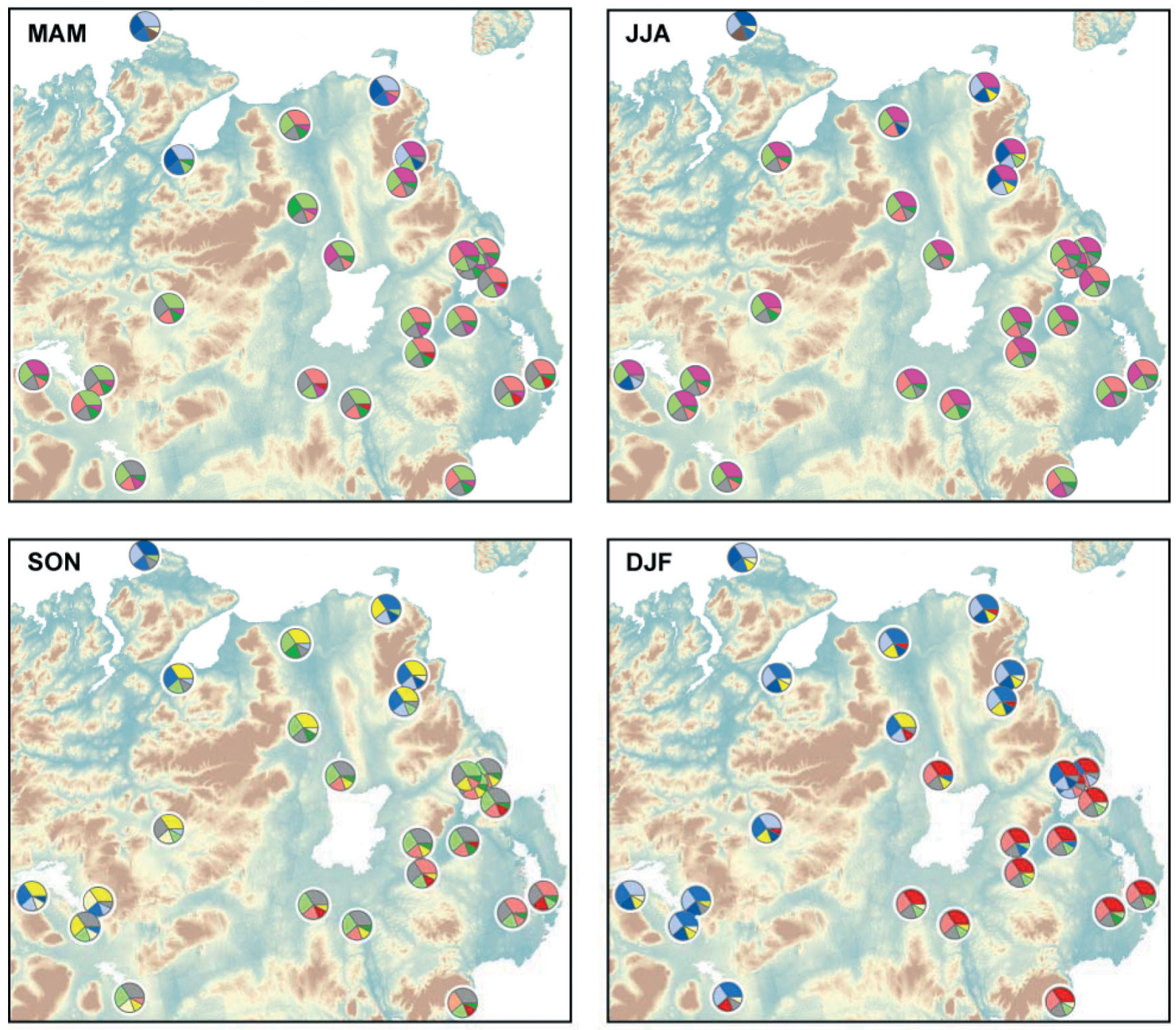

Near surface zonal velocity component $500 \mathrm{hPa}$ zonal velocity component $850 \mathrm{hPa}$ zonal velocity component Mean sea level pressure $500 \mathrm{hPa}$ geopotential height $850 \mathrm{hPa}$ geopotential height $500 \mathrm{hPa}$ airflow strength $850 \mathrm{hPa}$ airflow strength Near surface wind direction Near surface vorticity $850 \mathrm{hPa}$ vorticity

Near surface relative humidity
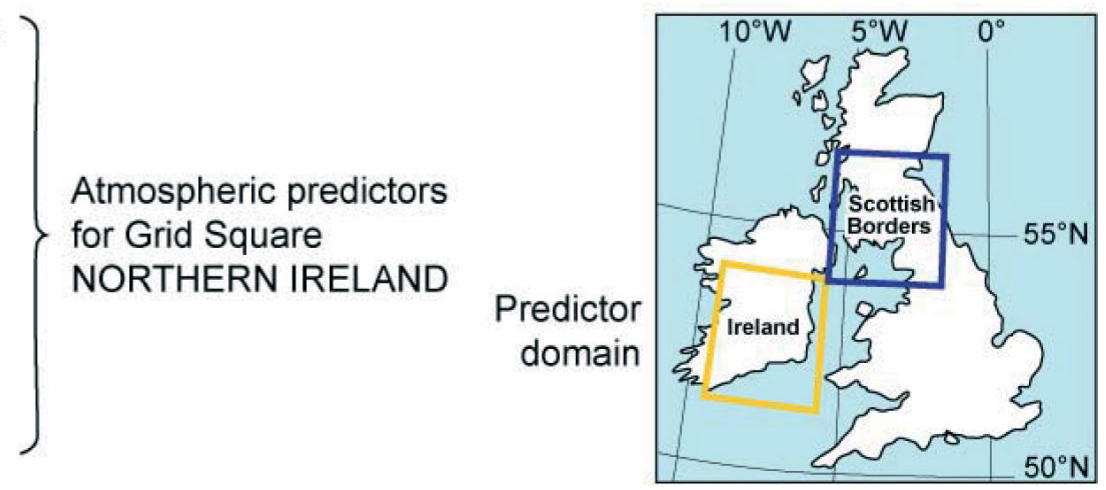

Fig. 5. Site-specific optimum predictor sets for Northern Ireland (NIR) when using the Northern Ireland (NIR) grid box (derived from the Scottish Borders [SB] and Ireland [IR] grid boxes). Site pie chart segment size reflects the ranked order of explained variance provided by each of the 5 optimum predictors (rank 1 largest to rank 5 smallest). MAM: March-May; JJA: June-August; SON: September-November; DJF: December-February 


\subsection{Magnitude of explained variance and grid-box selection}

Marked contrasts are readily apparent in both dominance and spatial pattern of site-specific optimum predictor sets relating to IR and NIR grid-box data (Figs. 4 \& 5). So which is the appropriate grid-box selection for undertaking a SDSM procedure for the assessment of regional climate change impacts in NIR? Comparison of the site-specific values of maximum and median explained variance relating to the predictor sets for IR and NIR grid boxes, identifies seasonal variations in strength of explanation utilising each grid set (Fig. 6).

In summer, NIR grid-box data consistently provide the highest $\mathrm{r}^{2}$ values. This is less evident in spring, when IR grid-box data provide the best explanation in the west and north. In autumn and winter IR grid-box data generally provide the best explanation, with highest $\mathrm{r}^{2}$ values derived from the NIR grid box confined to southeast stations. Grid-box contrasts in the percentage of explained variance at each site appear relatively minor, although in the context of precipitation models, the values represent marked differences. Absolute amounts of explained variance are relatively low $(\sim 25 \%)$, but with very many contributing pairs of daily values the significance is high, and even a small change in explained variance is important.

Fig. 7 illustrates the explained variance at the sample sites of Annalong and Lough Cowey in the southeast, Ballinamallard in the west and Carmoney in the north (Sites 1, 3, 2 and 4, respectively, in Fig. 6). Marked and consistent differences between grid boxes are evident. Generally, the grid box producing the greater amount of explained variance does so by $\sim 5 \%$. For climate-impacts assessors creating daily rainfall SD models in which 'improvement' in the percentage of explained variance is at a premium, this is an attractive gain. Indeed, the value of explained variance in the present study compares favourably with SD models in Wales of $30 \%$ (Mountain 2004), $28 \%$ in a study by Wilby et al. (2002) using SDSM, and $18 \%$ in a study by Wilby et al. (2000) using a downscaling method similar to that employed by SDSM.

These contrasting temporal and spatial patterns in strength of explanation utilising each grid set (Figs. 6 \& 7) are also reflected in the variations of the optimum predictor sets identified in Figs. 4 \& 5. This emphasises the importance of choice of predictor variable and spatial extent of corresponding predictor domain in ensuring the realism and stability of downscaled precipitation scenarios (Wilby \& Wigley 2000).
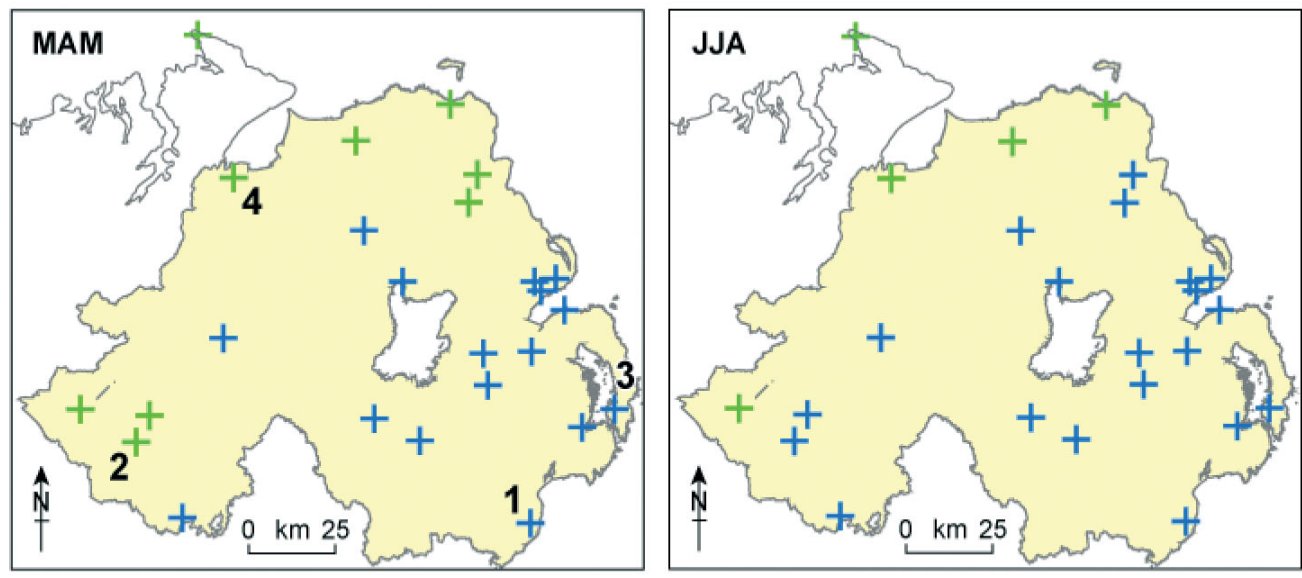

\section{+ Northern Ireland Grid Square \\ + Ireland \\ Grid Square}
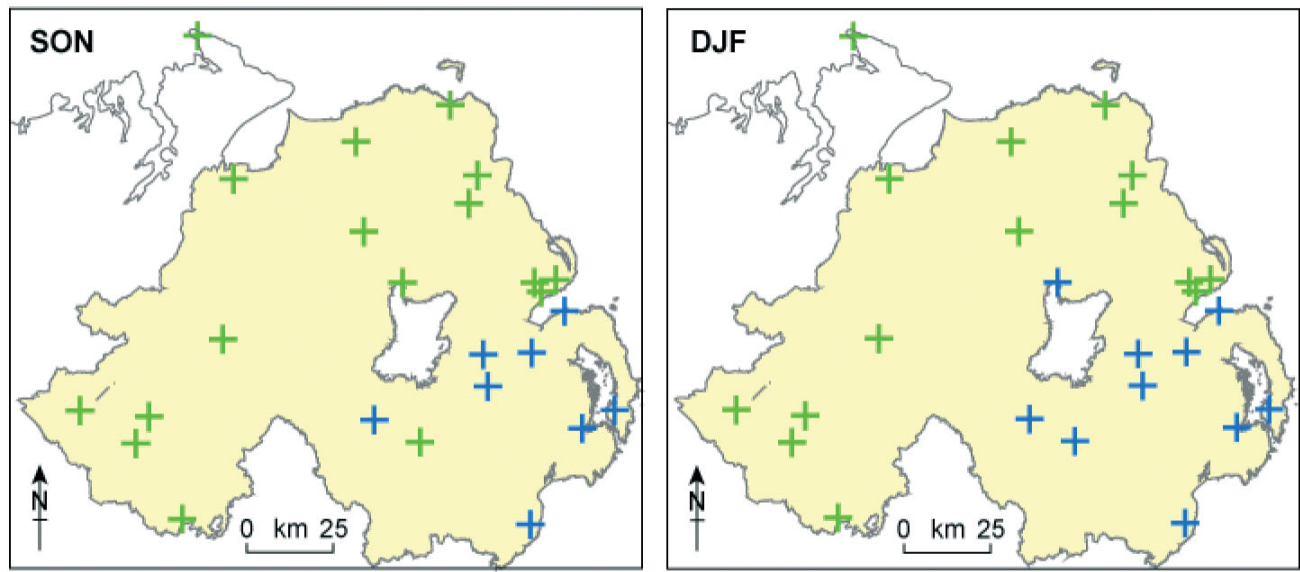

Fig. 6. Site-specific identification of the maximum and median $\mathrm{r}^{2}$ values relating to the Republic of Ireland (IR) grid box (green cross) or Northern Ireland (NIR) grid box (blue cross). MAM: March-May; JJA: June-August; SON: September-November; DJF: December-February. Numbers in MAM panel1: Annalong; 2: Ballinamallard; 3: Lough Cowey;

$$
\text { 4: Carmoney }
$$


Fig. 7. Comparison of seasonal explained variance (\%) of optimum predictor sets relating to the $\mathrm{Re}$ public of Ireland (IR) and Northern Ireland (NIR) grid-box data at sample sites. MAM: March-May; JJA: June-August; SON: September-November; DJF: December-February
(1) Annalong

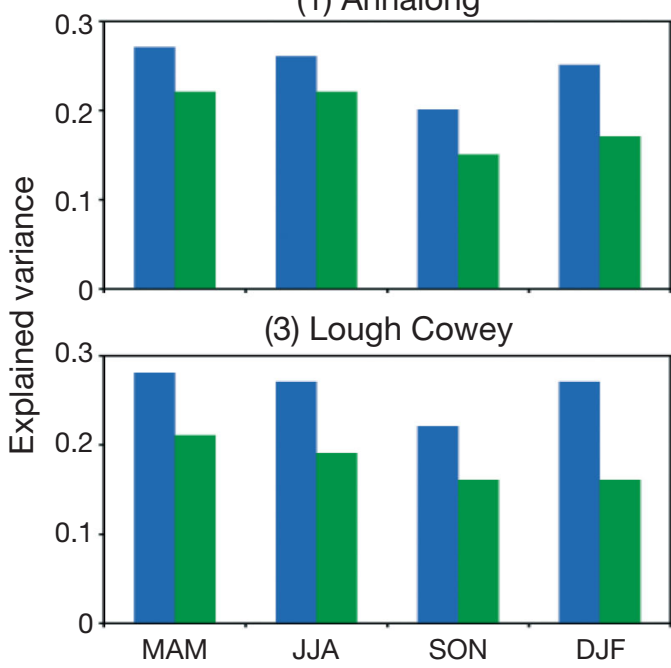

(2) Ballinamallard

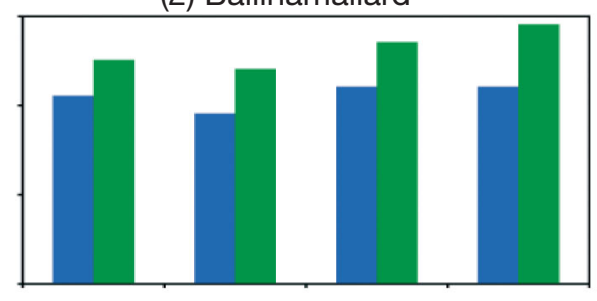

(2) Carmoney

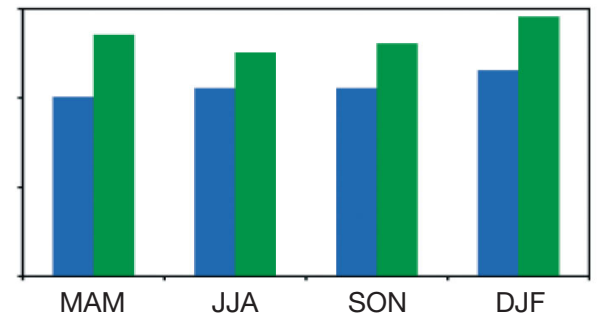

\subsection{Projections of daily precipitation intensity}

It is important to ascertain if choice of climate model grid box and associated predictors significantly impacts upon the results of a statistical downscaling application. SDSM version 3.1 was used to generate local daily precipitation intensity (mean precipitation on rain days, i.e. days with $>0.3 \mathrm{~mm}$ ) scenarios under baseline (1961-1990) and future (2060s) climate forcing for the rainfall station Ballinamallard, County Fermanagh (Fig. 3). The site displayed markedly different optimum predictor sets for the IR and NIR grid boxes (Figs. 4 \& 5), making it useful to gauge the impact of box selection. Optimum predictor sets were identified from the UKSDSM candidate predictor suite (Table 1).

Downscaling utilised 3 leading GCMs; the Hadley Centre HadCM3 coupled ocean-atmosphere climate model (Gordon et al. 2000), the Canadian Centre for Climate Modelling and Analysis CGCM2 model (Flato et al. 2000), and the Max-Planck-Institut für Meteorologie - Deutsches Klimarechenzentrum ECHAM4 model (Roeckner et al. 1996), and assuming the SRES A2 emissions scenario.

SD of the Ballinamallard data for the 2060s indicates a markedly more pronounced increased precipitation intensity using the NIR grid box (Fig. 8). Increased intensity prevails throughout the year in 2 models (HAD and ECHAM), with pronounced peaks in August and November. Only the CGCM estimates any future reduction in precipitation intensity. In contrast, using the IR grid box, the precipitation intensity feature is for a marginal increase in winter and marginal decrease in summer.

Use of SD methods is motivated by an assumption that GCMs simulate grid-box scale predictors better than sub grid-box scale processes such as precipitation
(Murphy 2000). SD model users therefore need to be aware of a GCM's ability to simulate each predictor identified in the optimum sets. Wilby \& Wigley (2000) noted that GCM predictors have rarely been assessed in ways that mesh with their application to downscaling. This criterion for predictor selection is a subject of continued SDSM research (Wilby \& Dawson 2007).

Furthermore, the credence attached to each scenario for the 2060s will be greater for a GCM that best replicates the observed precipitation climatology. Assessment is required of the 3 GCMs' abilities to downscale observed monthly precipitation characteristics for the Ballinamallard site. Fig. 9 provides visual assessment of each GCM's performance at replicating the STARDEX (STAtistical and Regional dynamical Downscaling of EXtremes for European regions) diagnostic tests (Goodess et al. 2003) for daily precipitation characteristics, using examples from the IR grid box, deemed more appropriate for downscaling than the NIR grid box (see Figs. $7 \& 8$ and Section 6.3). All 3 GCMs successfully replicate mean daily intensity and the 90th percentile of daily rainfall amounts for Ballinamallard. CGCM displays least skill at replicating maximum $5 \mathrm{~d}$ totals and peaks over the 90th percentile, being most notable in May and August. For these more 'extreme' descriptors of persistent and oneoff events respectively, the SD model may require additional or different predictors. This is physicallyrealistic because even at this westerly site which shows strongest relationships with Atlantic influences (e.g. zonal components), predictors linked to extremes of summer precipitation are likely to represent much more 'local' controls. None of the GCMs are skilful at reproducing maximum dry spell length. This is a function of event rarity during a $30 \mathrm{yr}$ time slice, for even dry spells $\left(<0.3 \mathrm{~mm} \mathrm{~d}^{-1}\right)$ of more than 3 or $4 \mathrm{~d}$ are 


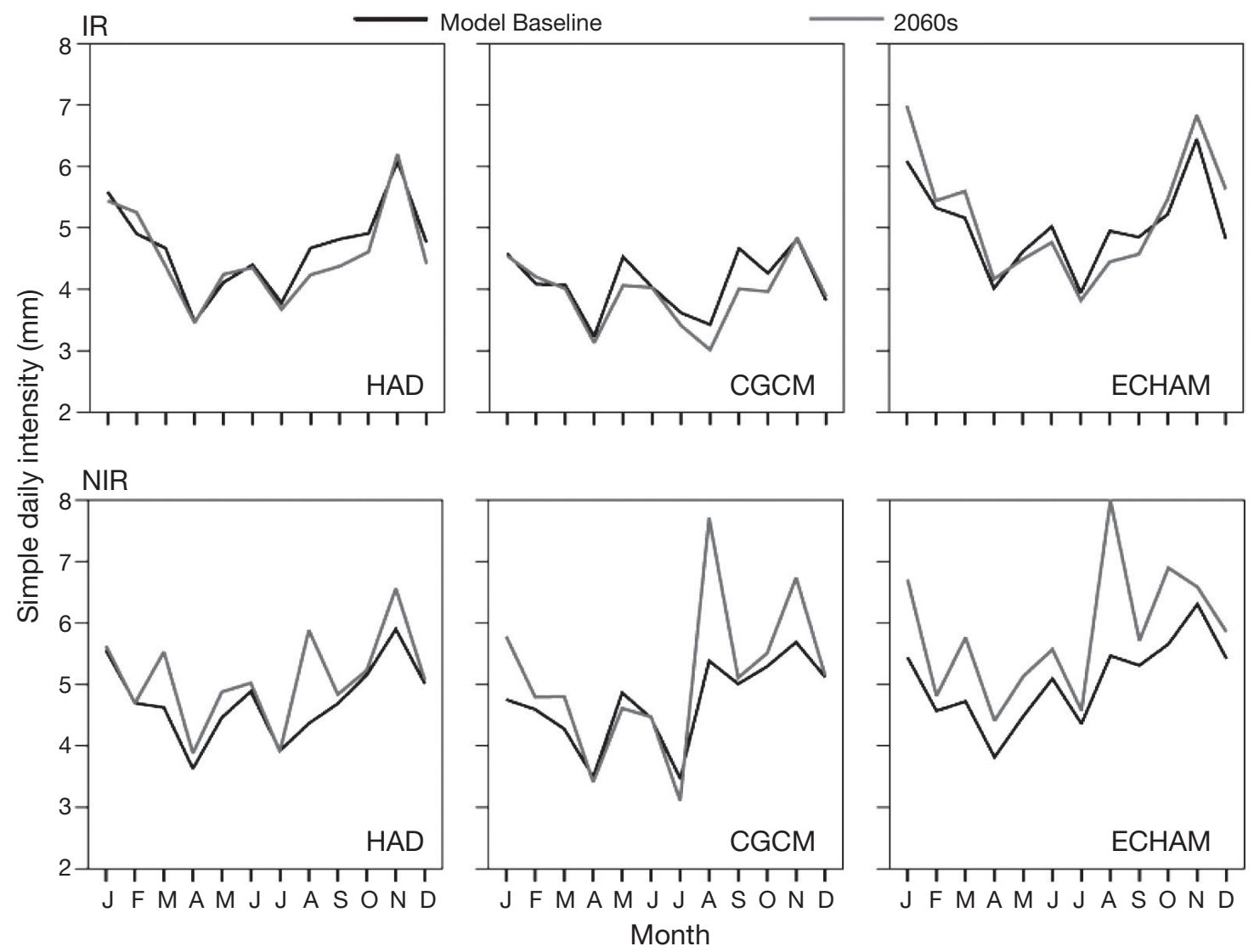

Fig. 8. Contrasting projections for 2060s of simple daily precipitation intensity ( $\mathrm{mm}$ ) for Ballinamallard using predictor variables from the Republic of Ireland (IR) and Northern Ireland (NIR) grid boxes. (NB: STARDEX indices were estimated from a single ensemble member produced by SDSM, and thus no attempt has been made to assess the statistical significance of any apparent differences between results from the IR and NIR grid boxes)

uncommon in NIR. Overall, HAD and ECHAM display greatest skill at reproducing the observed precipitation climatology.

Such variability has implications for future projections. Climate-impacts assessors now typically work with multiple GCMs/emissions scenarios, in order to capture some of the first-order uncertainty due to these components. Wilby \& Harris (2006), in their uncertainty analysis of future low flows in the River Thames, ranked the relative significance of climateimpacts modelling components as follows (greatest to least): (1) GCM, (2) empirical downscaling method, (3) hydrological model structure, (4) hydrological model parameters, (5) emissions scenario. Crawford (2007) concurred with this relative order of significance in a hydrological impacts study of NIR. Thus, choices about GCM and downscaling technique are highly significant for the outputs of climate-impacts assessment.

Acknowledging that these analyses relate to only one exemplar station, it is evident that in the case of NIR, choice of predictor variables and grid boxes can impact upon SD outcomes.

\section{DISCUSSION}

Determination of the relative appropriateness of data from the IR and NIR grid boxes to downscaling precipitation for NIR involves both geographical and climatological factors. Geographically, the centre of gravity of the IR grid box is mid-Ireland, but shifts northeast into the Irish Sea for the NIR grid box. Application of the IR box will highlight maritime Atlantic influences upon selection of precipitation predictor variables. In contrast the eastward shift associated with the NIR grid box will likely produce the characteristics of a precipitation regime that is leeward of the dominant maritime influence. The seasonal spatial patterns of site-specific optimum predictor sets for NIR (Figs. 4 \& 5), and maximum explained variance for the IR and NIR grid boxes (Figs. 6 \& 7) exemplify these influences.

\subsection{Predictor output from the IR grid box}

Predictor output demonstrates prominence of westeast penetration of Atlantic influences across NIR in 


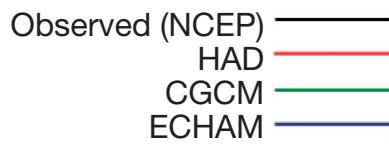

Fig. 9. Ability of each GCM to replicate observed (NCEP) rainfall characteristics (STARDEX diagnostic tests) for the Ballinamallard site, using the Republic of Ireland (IR) grid box
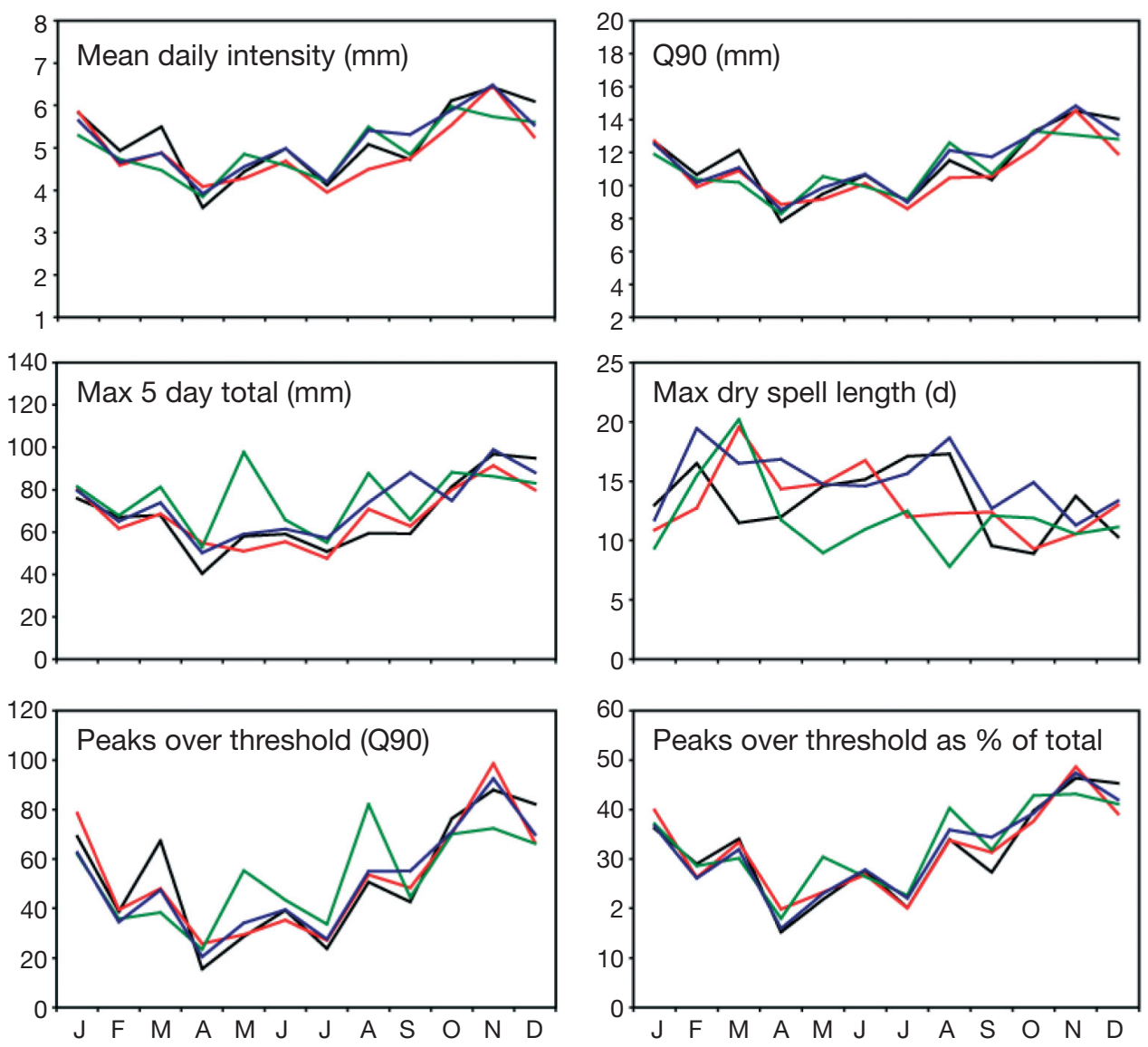

autumn and winter, and subsequent westward retreat of these influences in spring and summer. Continental influences are least marked in autumn when the sea surface/land temperature gradient is at a minimum, due to the decline in maximum inland air temperature. Hence, convectional activity is limited, as reflected by the reduced importance of vorticity as a predictor variable for autumn precipitation. Airflow strength predictors are important at this season, reflecting the prevalence of a progressive zonal circulation regime and storms at this period (Betts 1997), and which push eastward continental influences. In contrast, airflow strength is not important as a precipitation predictor in spring and summer. At these seasons, inherent shortening of the upper airflow pattern induces a decline in maritime westerly influence, reduces wind speeds and, particularly in spring, allows extension of the continental anticyclone towards NIR, thereby promoting greater frequencies of dry spells. Such continental influence is indicated by geopotential height and $850 \mathrm{hPa}$ vorticity as important predictors over the southeast of NIR. In the west and north, maritime westerly influences remain prominent in spring and summer, as reflected by the importance of zonal velocity predictor variables. These patterns also reflect the sharpened south-north pressure gradient that occurs across the IR and NIR in summer due to the northward displacement of the Azores High (Betts 1997). Relative humidity is an important control everywhere in spring and summer, since this parameter experiences its greatest range at these seasons. As a result of these factors, particularly in summer, the main focus of convective activity is over land, especially the warmer areas of the east, where thunder frequencies have a marked summer peak. The east thus gains a convective summer rainfall component that balances out its annual regime of precipitation. Daily extremes of rainfall tend not to be associated with frontal passages alone, but rather where orographic and/or convectional enhancement occurs, especially in summer.

In winter, with juxtaposition of strong thermal contrasts between land and sea, oceanic warmth assists transfer of sensible and latent heat to the atmosphere. IR grid-box data identify convection and vorticity parameters as prominent precipitation predictors in the southeast of NIR at this season. This area is afforded some protection from westerly influences by adjacent upland, and is exposed to southeast and cyclonic southeast airflows. In winter, with a long fetch across the relatively warm Irish Sea, vorticity is enhanced within these airstreams. In contrast, vorticity is not a key precipitation predictor along the Irish Sea coast- 
line of County Antrim, despite exposure to southeast and cyclonic southeast airflow (Fig. 4). Examination of the trajectory of these airflows suggests the possibility of dissipation of precipitation over the Southern Uplands of Scotland prior to reaching the North Antrim Plateau.

Away from the southeast, in winter a maritime westerly influence prevails over the west and northwest of NIR. Continual exposure of these areas to eastward progressive depressions and frontal precipitation at this season is exemplified by the importance of zonal velocity and airflow strength predictors at all sites.

Of other IR grid-box predictors, relative humidity is not important as a predictor in autumn and winter due to its high value throughout these seasons. Mean sea level pressure is only significant as a predictor in the southeast of NIR. It is prominent at all seasons, but particularly in autumn and winter, when the greatest variance of pressure values occurs. In summer, again it may be indicative of convective activity.

\subsection{Predictor output from the NIR grid box}

NIR grid-box predictor output displays weaker spatial contrasts in spring and summer than its IR counterpart. This is particularly evident with the more widespread importance of vorticity and geopotential height as precipitation predictors at these seasons associated with NIR grid-box output. It reflects the influence of the SB component, which is leeward of the dominant maritime influence generally found throughout NIR and IR. For example, in summer, localised convection can enhance thunderstorm activity moving inland from the Solway coast and promote greater potential for producing remarkable falls (Harrison 1997) than occurs in NIR. Importance of mean surface pressure throughout the year indicates enhanced significance of proximity to depression tracks by incorporating the SB grid box. Significant also, in comparison with IR gridbox output, is the failure of maritime westerly influences (as indicated by zonal velocity predictor variables) to remain prominent in spring and summer in the west and north. Inclusion of the SB grid-box data suppresses identification of the sharpened south-north pressure gradient that occurs across the IR and NIR in summer due to the northward displacement of the Azores High. However, as with the IR grid box, relative humidity is important everywhere in spring and summer as a precipitation predictor.

In autumn, return of maritime westerly influences encroaching eastwards across NIR, as with the IR grid box, is indicated in the NIR box by the key predictor $500 \mathrm{hPa}$ airflow strength in the west and north west of NIR. Continental influence remains evident in the east exemplified by vorticity predictors. Mean sea level pressure, a key predictor everywhere, is indicative of the significant role of Atlantic depressions at this season.

In winter, the NIR grid box displays similar southeast-northwest contrasts of predictors to that found in IR grid-box output. Greater spatial extent of vorticity as a prominent predictor in the former grid box (Fig. 5) may represent an accentuation of the influence of convection associated with easterly airstreams passing over the Irish Sea and North Sea. This is indicative of the character of the climate regime associated with the SB grid box, encompassing an area that experiences greater contrasts of climate variability involving maritime and continental influences at this season than that associated with the IR grid box.

It is apparent, that both IR and NIR grid-box data sets identify meaningful key predictors of precipitation occurrence that can be explained in terms of local climate and large-scale atmospheric processes.

\subsection{Recommendations for grid-box selection}

In terms of grid-box selection, both IR and NIR grid boxes produce climatologically meaningful predictors of precipitation. Just as Brinkmann (2002) and DiazNieto \& Wilby (2005) show that it is not necessarily the grid box overlying the local observations that provides the best predictive skill, in the application of a SD procedure for NIR, the use of the IR grid box appears more appropriate for 2 reasons. First, with NIR occupying an ocean box in GCMs, the statistical downscaling process is land-driven, hence geographically, use of the nearest, adjacent terrestrial box (IR grid box) is appropriate. Second, the set of site-specific predictors for the IR box reflect more closely the Irish climatic mosaic than the output from the NIR grid box.

Application of a limited statistical downscaling procedure to a single site (Fig. 8) to some extent also supports adoption of the IR grid box in the context of similarity of currently accepted future precipitation intensity scenarios for the region. Current UK Climate Impacts Programme (UKCIP02) projections (using HAD climate models) indicate an increase in winter daily precipitation intensity, a slight increase in spring, less intense in summer and a small increase in autumn over NIR by the 2060s (Hulme et al. 2002). Similarity of currently accepted future precipitation intensity scenarios for a region, however, is not necessarily a firm basis on which to justify adoption of the IR grid box in preference to the NIR grid box. Had the UKCIP2002 scenarios been derived from CGCM2 or ECHAM4 boundary forcing, the precipitation scenarios might have looked very different for the IR grid box. 
Despite the complicating land-sea masking issues associated with western margins of continents, these maritime regions yield downscaling outputs of relatively high skill compared with continental sites and eastern continental margins (McCabe \& Dettinger 1995, Goodess \& Palutikof 1998). For example, Goodess \& Jones (2002) and Mountain (2004) highlight how sites in Western Europe have the strongest relationships with precipitation predictors reflecting the dominant influence of Atlantic zonal airflow transporting moisture directly from the ocean.

We suggest that climate-impacts modellers working elsewhere in the globe, using a SDSM process to create future climate scenarios for areas on the western margins of continental landmasses, will need to follow a similar procedure to that outlined in this paper in order to ascertain which are the most appropriate GCM grid boxes for their study. This is likely to be particularly necessary where, as in NIR, the area of interest is a land area in an oceanic GCM grid box.

\section{CONCLUSIONS}

SDSM version 3.1 represents an example of userfriendly software whose uptake will encourage awareness of the utility of SD techniques by the climateimpacts community. There exists, however, a tendency in the application of SD methods to select predictor variables chosen on the basis of sensible physical relationships, but ignoring any comprehensive assessment of them. Similarly, the choice of climate model grid box(es) for downscaling is often somewhat arbitrary. Indeed, Diaz-Nieto \& Wilby (2005) recently raised these two issues in relation to climate change scenarios and low flows in the River Thames, southeast England.

With an oceanic location ensuring that equability is a major feature of the NIR climate regime, constant alteration in airstream dominance promotes an equally striking characteristic of variability (Betts 1997). Complemented by a complex interplay of relief and oceanic influences, the NIR case study highlights the need for greater emphasis to be placed upon choice of predictors, and the impact of grid-box selection upon the final output of SD. It is suggested that these requirements are particularly pertinent in attempting $\mathrm{SD}$ in regions where, as with NIR, the land area is typically represented by an oceanic grid box in GCM experiments. Without careful assessment ensuring the selected grid box(es) are successfully identifying local climate and large-scale atmospheric processes and relationships within the study area, a problem may arise over the appropriateness of model output within the selected box(es) for application to future climate change scenarios for the region. Climate-impacts modellers working in similarly-sited land areas (i.e. on the western margin of continental landmasses, particularly those situated in oceanic GCM grid boxes) would be well advised to follow a similar procedure to that outlined in the present study.

Acknowledgements. The authors gratefully acknowledge the technical advice offered by R. L. Wilby (Environment Agency of England and Wales) and C. Dawson (Loughborough University). Figures prepared by M. Pringle (QUB Cartography Department).

\section{LITERATURE CITED}

Abaurrea J, Asín J (2005) Forecasting local daily precipitation patterns in a climate change scenario. Clim Res 28:183-197

Barrow E, Hulme M, Semenov MA (1996) Effect of using different methods in the construction of climate change scenarios: examples from Europe. Clim Res 7:195-211

Beckmann BR, Buishand TA (2002) Statistical downscaling relationships for precipitation in the Netherlands and North Germany. Int J Climatol 22:15-32

Benestad RE (2001) A comparison between 2 empirical downscaling strategies. Int J Climatol 21:1645-1668

Bernardi M, Gommes R, Grieser J (2006) Downscaling climate information for local disease mapping. Parassitologia 48(1-2): 69-72

Betts NL (1997) Climate. In: Cruickshank JG (ed) Soil and environment: Northern Ireland. Department of Agriculture for Northern Ireland and Queen's University Belfast, Belfast, p 63-84

Betts NL (2002a) Water resources. In: Smyth A, Montgomery WI, Favis-Mortlock D, Allen S (eds) Implications of climate change for Northern Ireland: informing strategy development. The Stationery Office Limited, Norwich, p 48-63

Betts NL (2002b) Climate change in Northern Ireland. In: Smyth A, Montgomery WI, Favis-Mortlock D, Allen S (eds) Implications of climate change for Northern Ireland: informing strategy development. The Stationery Office Limited, Norwich, p 26-42

Bootsma A, Gameda S, McKenney DW (2005) Impacts of potential climate change on selected agroclimatic indices in Atlantic Canada. Can J Soil Sci 85:329-343

Brinkmann WAR (2002) Local versus remote grid points in climate downscaling. Clim Res 21:27-42

Cavazos T, Hewitson BC (2005) Performance of NCEP-NCAR reanalysis variables in statistical downscaling of daily precipitation. Clim Res 28:95-107

Conway D, Wilby RL, Jones PD (1996) Precipitation and air flow indices over the British Isles. Clim Res 7:169-183

Crawford T (2007) Future climate change: modelling the implications of shifts in rainfall characteristics for runoff in Northern Ireland. PhD thesis, Queen's University Belfast, Belfast

Diaz-Nieto J, Wilby RL (2005) A comparison of statistical downscaling and climate change factor methods: impacts on low flows in the River Thames, United Kingdom. Clim Change 69:245-268

Flato GM, Boer GJ, Lee WG, McFarlane NA, Ramsden D, Reader MC, Weaver AJ (2000) The Canadian Centre for Climate Modelling and Analysis global coupled model and its climate. Clim Dyn 16:451-467

Goodess CM, Jones PD (2002) Links between circulation and changes in the characteristics of Iberian rainfall. Int J Climatol 22:1593-1615

Goodess CM, Palutikof JP (1998) Development of daily rainfall scenarios for southeast Spain using a circulation-type approach to downscaling. Int J Climatol 10:1051-1083 
Goodess C, Osborn T, Hulme M (2003) The identification and evaluation of suitable scenario development methods for the estimation of future probabilities of extreme weather events. Technical Report 4. Tyndall Centre for Climate Change Research, School of Environmental Sciences, University of East Anglia, Norwich

Gordon C, Cooper C, Senior CA, Banks H, Gregory JM, Johns TC, Mitchell JFB, Wood RA (2000) The simulation of SST, sea ice extents and ocean heat transports in a version of the Hadley Centre coupled model without flux adjustments. Clim Dyn 16:147-168

Hanssen-Bauer I, Achberger C, Benestad RE, Chen D, Førland EJ (2005) Statistical downscaling of climate scenarios over Scandinavia. Clim Res 29:255-268

Harpham C, Wilby RL (2005) Multi-site downscaling of heavy precipitation occurrence and amounts. J Hydrol 312:235-255

Harrison SJ (1997) Central and southern Scotland. In: Wheeler D, Mayes J (eds) Regional climates of the British Isles. Routledge, London, p 205-227

Haylock MR, Cawley GC, Harpham C, Wilby RL, Goodess CM (2006) Downscaling heavy precipitation over the United Kingdom: a comparison of dynamical and statistical methods and their future scenarios. Int J Climatol 26:1397-1415

Hewitson BC, Crane RG (1996) Climate downscaling: techniques and application. Clim Res 7:85-95

Hulme M, Jenkins GJ (1998) Climate change scenarios for the UK: scientific report. UKCIP Technical Report No. 1. Climatic Research Unit, Norwich

Hulme M, Jenkins GJ, Lu X, Turnpenny JR and 8 others (2002) Climate change scenarios for the United Kingdom: the UKCIP02 scientific report. Tyndall Centre for Climate Change Research, School of Environmental Sciences, University of East Anglia, Norwich

Huth R (2005) Downscaling of humidity variables: a search for suitable predictors and predictands. Int J Climatol 25: 243-250

IPCC (2001) Climate change 2001: the scientific basis. Contribution of Working Group I to the Third Assessment Report of the Intergovernmental Panel on Climate Change. Houghton JT, Ding Y, Griggs DJ, Noguer M, van der Linden PJ, Dai X, Maskell K, Johnson CA (eds) Cambridge University Press, Cambridge

IPCC-TGCIA (1999) Guidelines on the use of scenario data for climate impact and adaptation assessment. Version 1. Prepared by Carter TR, Hulme M, Lal M. Intergovernmental Panel on Climate Change, Task Group on Scenarios for Climate Impact Assessment

Khan MS, Coulibaly P, Dibike Y (2006) Uncertainty analysis of statistical downscaling methods using Canadian Global Climate Model predictors. Hydrol Process 20:3085-3104

McCabe GJ, Dettinger MD (1995) Relations between winter precipitation and atmospheric circulation simulated by the Geophysical Fluid Dynamic Laboratory General Circulation Model. Int J Climatol 15:625-638

McCurdy D, Stewart B (2003) A discussion paper on climate change and forestry in Nova Scotia: ecological implications and management options. Forest research report FOR 2003-4, Nova Scotia Department of Natural Resources Forest Management Planning, Truro

Mountain NC (2004) Modelling the impact of climate change on the hydrology of the Elan and Wye catchments, Mid-Wales. $\mathrm{PhD}$ thesis, University of Wales, Aberystwyth,
Murphy J (2000) Predictions of climate change over Europe using statistical and dynamical downscaling techniques. Int $\mathrm{J}$ Climatol 20:489-501

Pilling CG, Jones JAA (2002) The impact of future climate change on seasonal discharge, hydrological processes and extreme flows in the Upper Wye experimental catchment, mid-Wales. Hydrol Process 16:1201-1213

Prudhomme C, Reynard N, Crooks S (2002) Downscaling of global climate models for flood frequency analysis: where are we now? Hydrol Process 16:1137-1150

Roeckner E, Oberhuber JM, Bacher A, Christoph M, Kirchner I (1996) ENSO variability and atmospheric response in a global coupled atmosphere-ocean GCM. Clim Dyn 12:737-754

Rummukainen M (1997) Methods for statistical downscaling of GCM simulation. SWECLIM report. Rossby Centre, Norrköping

Schmidt M, Glade T (2003) Linking global circulation model outputs to regional geomorphic models: a case study of landslide activity in New Zealand. Clim Res 25:135-150

Thomson AM, Brown RA, Ghan SJ, Cesar Izaurralde R, Rosenberg NJ, Leung LR (2002) Elevation dependence of winter wheat production in eastern Washington State with climate change: a methodological study. Clim Change 54(1-2): 141-164

UNFCCC (United Nation Framework Convention on Climate Change) (2005) Compendium on methods and tools to evaluate impacts of, and vulnerability and adaptation to, climate change. UNFCCC Secretariat, Bonn

Wagener T, Franks S, Gupta HV, Bøgh E, Bastidas L, Nobre C, de Oliveira Galvão C (eds) (2005) Regional hydrological impacts of climatic change-impact assessment and decision making. IAHS Press, Wallingford

Wilby RL, Dawson CW (2004) Using SDSM version 3.1-A decision support tool for the assessment of regional climate change impacts. Environment Agency of England and Wales, Nottingham

Wilby RL, Dawson CW (2007) SDSM 4.1-A decision support tool for the assessment of regional climate change impacts. Environment Agency of England and Wales, Nottingham

Wilby RL, Harris I (2006) A framework for assessing uncertainties in climate change impacts: low flow scenarios for the River Thames, UK. Water Resour Res 42:W02419.1-W02419.10

Wilby RL, Wigley TML (1997) Downscaling general circulation model output: a review of methods and limitations. Progr Phys Geogr 21(4):530-548

Wilby RL, Wigley TML (2000) Precipitation predictors for downscaling: observed and general circulation model relationships. Int J Climatol 20:641-661

Wilby, RL, Arritt RW, Takle ES, Pan Z, Leavesley GH, Clark MP (2000) Hydrological responses to dynamically and statistically downscaled climate model output. Geophys Res Lett 27: 1199-1202

Wilby RL, Dawson CW, Barrow EM (2002) SDSM - a decision support tool for the assessment of regional climate change impacts. Environ Model Software 17:147-159

Wilby RL, Charles SP, Zorita E, Timbal B, Whetton P, Mearns LO (2004) Guidelines for use of climate scenarios developed from statistical downscaling methods. Available at: http://ipccddc.cru.uea.ac.uk/guidelines/dgm_no2_v1_09_2004.pdf

Zorita E, von Storch H (1999) The analog method as a simple downscaling technique: comparison with more complicated methods. J Clim 12:2474-2489

Submitted: December 27, 2005; Accepted: May 30, 2007

Proofs received from author(s): July 4, 2007 